\title{
Effect of Application of Endotracheal Suction Guidelines on Cardiorespiratory Parameters of Mechanically Ventilated Patients

\author{
Suad Elsayed Elsaman PhD,RN
} \\ Department of Critical Care and Emergency Nursing, Faculty of Nursing, University of Alexandria, Egypt.
}

\begin{abstract}
Background One of the highly vital duties done by nurses in the intensive care units (ICU) is endotracheal suctioning (ES). It is done for maintaining airway and improving ventilation and oxygenation; however, it must be done in a way so that, in addition to the mentioned advantages, it can have the least complications for the patient. Kelher et al. ${ }^{(52)}$ showed that some nurses performed ES without consideration to recommended steps so excellence of this nursing intervention was less than predicted. Therefore practicing ES with adherence to recommended guidelines is an inquiry, so it is essential to examine routine ICU method of ES applied by nurses compared with standard one that is based on the guidelines.
\end{abstract}

Objective To evaluate Effect of application of endotracheal suction guidelines on cardiorespiratory parameters of mechanically ventilated patients.

Method 60 adult patients who admitted to ICU were included in this study. The tool "Cardiorespiratory parameters of mechanically ventilated patient record" was used to collect data. The period of study was from October 2012 to March 2013.

Results Regarding comparing between the standard versus routine ICU methods of endotracheal suction using open suction system, findings revealed that after the standard ES, there was significant improvement in respiratory tidal volume, partial pressure of arterial oxygen, and arterial oxygen saturation.

Conclusions the standard ES method had fewer side effects such as hemodynamic instability, hypoxemia and impaired ventilation when compared with routine ES one.

Key words : Cardiorespiratory, guidelines, nurse, open, routine, suction.

\section{Introduction}

Mechanical ventilation (MV) and tracheal intubation significantly impair airway secretion clearing causing endotracheal suctioning (ES) of secretions is necessary. Endotracheal suction is defined as: "A component of bronchial hygiene therapy which involves mechanical aspiration of pulmonary secretions from a patient with an artificial airway in place". It is achieved by nurses to obtain effective oxygenation. ${ }^{(1-4)}$

Despite the necessity of ES plus some patients reported that the procedure eases their breathing, this approach can lead to complications such as damage to the trachea, bleeding, infection, cardiovascular and hemodynamic disturbances, impaired blood gas exchange and hypoxemia, bronchoconstriction, atelectasis and increased intracranial pressure. Moreover, ES is a source of pain and discomfort for MV patients. This discomfort does not diminish during a course of MV; on the contrary, it may worsen. These complications lead to an increase in the patient's stay in hospital and intensive care unit (ICU). ${ }^{(5,6)}$

Technique of ES has a consequence on its harms and usefulness. Nowadays, two systems are available to perform ES: open suction system (OSS) and closed suction system (CSS). OSS requires disconnecting between patient and ventilator when performing suction, which is not necessary to do this disconnection with CSS. Moreover, CSS needs special designed catheter which is more expensive and not easy to be available. Clinical studies have demonstrated that OSS can cause alveolar decruitment and transient hypoxemia. ${ }^{(7,8)}$ In Egypt, OSS is the most common used technique because its suction catheter is less cost and more available.

Studies done by Day et al. ${ }^{(9)}$ and Pedersen et al. ${ }^{(10)}$ provided data on when and how to perform ES reflecting that some patients may receive several times of ES daily according to patient's need. ${ }^{(11,12)}$ In 2010 the American Association of Respiratory Care (AARC) published the AARC Clinical Practice Guidelines on ES of mechanically ventilated patients with artificial airway as ES is done if needed only; providing hyperoxygenation before, during and after ES; ES should be done without disconnection between patient and ventilator; avoiding routine normal saline instillation before ES; use CSS for adults with high FiO2, or PEEP; Suction tube dimeter is less than $50 \%$ the lumen of the endotracheal tube in adults, maximum suction duration is 
Effect of Application of Endotracheal Suction Guidelines on Cardiorespiratory Parameters of...

from 10 to 15 seconds. Failure to meet the guidelines in implementation of this procedure can result in numerous side effects. ${ }^{(13,14)}$

A few studies ${ }^{(15-18)}$ examined if guidelines for ES were tracked by nurses in ICU. The results demonstrated that nurses were often not alert of these guidelines. Moreover, they found that there was a considerable difference reflected in nurses' performance between ideal standard ES where nurses followed the recommended guidelines and actual routine technique when nurses didn't. ${ }^{(17-20)}$ Additionally, Day et al. ${ }^{(17)}$ and Sole et al. ${ }^{(19)}$ stated that practice of ES was not always based on current research recommendations, which may lead to inconsistent practice among nurses, affecting patients' experience and increasing health risks associated with ES so it is necessary to examine the actual routine method of ES practiced by nurses in ICU and its effect on patient's condition in comparison with the standard ES that follows evidenced based recommendation. Based on this, the aim of this study was to evaluate effect of application of endotracheal suction guidelines on cardiorespiratory parameters of mechanically ventilated patients.

\section{Research questions}

- Is there a difference between the effect of standard and routine ICU method of endotracheal suction on cardiorespiratory parameters of MV patients?

\section{Operational definition}

- Endotracheal suction in this study refers to endotracheal suctioning using open suction system.

- Standard endotracheal suction refers to guidelines based endotracheal suction.

- Routine endotracheal suction refers to endotracheal suction according to usual ICU care.

Design was quasi experimental.

\section{Materials and Method}

\section{Setting}

The study was achieved at Causality Care Unit namely unit one and General Intensive Care Unit namely unit three of Main university Hospital, University of Alexandria, Egypt.

Patients

A convenience sample of 60 adult critically ill patients of both genders was involved in the study based on the power analysis (Epi-Info program) with the following information (population size $=90$ over 3 months, expected frequency $=50 \%$, acceptable error $=5 \%$, confidence coefficient $=95 \%$.

Patients were selected according to inclusion criteria; hospitalized $<48$ hrs, diagnosed with respiratory failure, on mechanical ventilation with endotracheal tube\& pressure controlled mode, attached with arterial line, free of infection were included in this study. Exclusion criteria; V/S unstable, refractory hypoxemia (low oxygen saturation $\{\mathrm{SpO} 2<90 \%\}$ in spite of providing high oxygen concentration $\{\mathrm{FiO} 2 \geq 60 \%\})$ and diagnosed with chronic obstructive pulmonary disease.

Tool: The used tool was "Cardiorespiratory parameters of mechanically ventilated patient record". It was a developed tool by the researcher after reviewing the related literature ${ }^{(2,3,10,21-23)}$. It was used to gather data of cardiorespiratory parameters to compare between actual routine method practiced by nurses in ICU and guidelines based method that are restricted to evidenced based recommendations. It consisted of two parts:

Part 1: it includes data of patient's demographics, past health history, medical diagnosis and smoking.

Part 2: cardiorespiratory parameters record including cardiac parameters (HR and MAP), respiratory parameters $\left(\mathrm{RR}\right.$ and $\left.\mathrm{V}_{\mathrm{t}}\right)$, oxygenation parameters $\left(\mathrm{PaCO}_{2}, \mathrm{PaO}_{2}\right.$, and $\left.\mathrm{SaO}_{2}\right)$. All these parameters used to compare between the routine and standard technique of ES procedure.

Tool development, validity and reliability:

The tool was developed by the researcher based on reviewing the relevant literature ${ }^{(2,3,10,21-23)}$. The tool was reviewed for content validity, by professors in the following fields: critical care nursing, critical care medicine, anaesthesia and medical biostatistics. Based on their judgement, the required necessary modifications were done. The tool reliability was tested using internal consistency methods (Alpha Cronbach test) by using SPSS version 20 as following: in the tope toolbar select: Analyze > Scale > Reliability Analysis. Its result was $\alpha$ $=0.714$, which indicates an accepted reliability of the tool.

Pilot study:

A pilot study was carried out on five (12\%) patients who were recruited from study sample to test feasibility and applicability of the tool and necessary modification was done to prepare the tool for final form.

Method

An official approval was obtained from "head of Critical Care \& Emergency Nursing Department", and "Nursing Ethical Committee" of Nursing Faculty- Alexandria University and hospital authority "Medical Ethical Committee" after explaining the aim of study. An explanation about the aim and nature of present study 
Effect of Application of Endotracheal Suction Guidelines on Cardiorespiratory Parameters of...

was introduced to critical care unit administrators and nurses. Each nurse was informed that sharing in that study was voluntary.

Patients were selected based on the required criteria. Patients were randomly divided into two groups as following; each selected ICU setting had two halls, first hall patients were assigned to the control group and the second hall patients were assigned to the study group.

Thirty patients $(\mathrm{n}=30)$ in each group where:

The control group received routine ES according to usual ICU routine care.

The study group received standard ES based on the recommended guidelines

Data collection

Patient's related characteristics using part 1 of the developed tool were obtained for both groups. Collecting data process occurred once for each patient through three forms; assessing routine ES method for the control group, practicing standard ES method for the study group and recording cardiorespiratory parameters for both groups.

For the control group (routine ES method group):

Assessing routine ES method: the researcher assessing routine ES method applied by the assigned nurses as suctioning was done with its usual method with open suction system as following: selecting the suction catheter size did not follow specific principles as. Patient's hyper-oxygenation with $100 \%$ oxygen was not always done before, during or after ES. Sometimes suction catheter was entered into the tracheal tube when the suctioning device was switching on or off. There was no control on suction machine pressure level. Duration of suctioning did not have specific time and it was stopped when the nurse diagnosed that there was no remaining secretion.

For the study group (standard ES method group):

Practicing standard ES method: After assessing patient's need for ES as increased copious retained secretions in lung, $\mathrm{SpO}_{2}<90 \%$ and $\mathrm{V}_{\mathrm{t}}<300 \mathrm{ml}$. The researcher applied guidelines based ES method using open suction system based on the confirmed protocol of AARC ${ }^{(13)}$ as following: choosing suction tube size (for male $\&$ female patients) by the formula: endotracheal tube size $-2 \times 2 \mathrm{~cm}$. Suction pressure was controlled from 120 to $150 \mathrm{mmHg}$. The patient was hyper-oxygenated for one minute with $100 \%$ oxygen before ES. Peripheral oxygen salutation $\mathrm{SpO}_{2}$ and heart rate were checked. The suction catheter was brought down to patient's trachea until resistance (max: 6 inches $=15 \mathrm{~cm}$ ) was met then the catheter was drawn about $2 \mathrm{~cm}$. The suctioning machine was then switched on and suctioning was done for a maximum of 15 seconds then suction tube was removed and patient was attached to MV and again the patient was hyper-ventilated for one minute with $100 \%$ oxygen in between suction passes and after suction. $\mathrm{SpO}_{2}$ and $\mathrm{HR}$ were rechecked. ${ }^{(10,13)}$

For both groups:

Recording cardiorespiratory parameters: The researcher recorded cardiorespiratory parameters (MAP, HR, $\mathrm{RR}, \mathrm{V}_{\mathrm{t}}, \mathrm{PaCO}_{2}, \mathrm{PaO}_{2}$ and $\mathrm{SaO}_{2}$ ) using part 2 of the tool. $\mathrm{HR}$ was obtained from radial pulse. Blood pressure was measured manually then MAP was calculated by formula of (systolic blood pressure +2 diastolic blood pressure)/3. An arterial blood sample was taken from arterial line four times; immediately before, after 1, 10, and 30 min after suctioning to determine $\mathrm{PaCO}_{2}, \mathrm{PaO}_{2}$, and $\mathrm{SaO}_{2}$.

To evaluate effect of the standard against routine ES method on cardiorespiratory parameters of patients attached with MV, comparison was done between the two groups regarding readings of cardiorespiratory parameters before and after ES.

\section{Administrative and ethical considerations}

The study was done at about seven months (March 2012 - September 2013). Informed written consent was obtained from conscious patient or family member (if unconscious patient), after explaining the potential benefits and hazards from participation. The anonymity, privacy, confidentiality, and the right to refuse to participate in the study were assured.

\section{Statistical analysis of the data ${ }^{(24)}$}

Data were fed to the computer and analyzed using IBM SPSS software package version 20. ${ }^{(25)}$ Analysis and interpretation of data were done using the followings; Frequency, mean and standard deviation and t-test were used to test the significance of results of quantitative variables. P is significant if $\leq 0.05$.

\section{RESULTS}

Table 1 presents the sample distribution according to patients' characteristics. The mean age value was $46.20 \pm 12.81$ in the control group and $44.73 \pm 13.88$ in the study group. Most patients were non-smoker in both of the control and study groups ( 83.3 and $73.3 \%$ correspondingly). On admission, about half of patients of the control and study groups had diagnosis related to respiratory and other disorders $(46.67 \%$ and $56.7 \%$ correspondingly). The difference between the control and study groups as regards sex, age, presence of history of respiratory disease, smoking and current diagnosis were statistically non-significant $(\mathrm{p}=0.795,0.672,0.744$, 0.347 and 0.740 correspondingly). 
Table 1: Sample distribution according to patients' characteristics

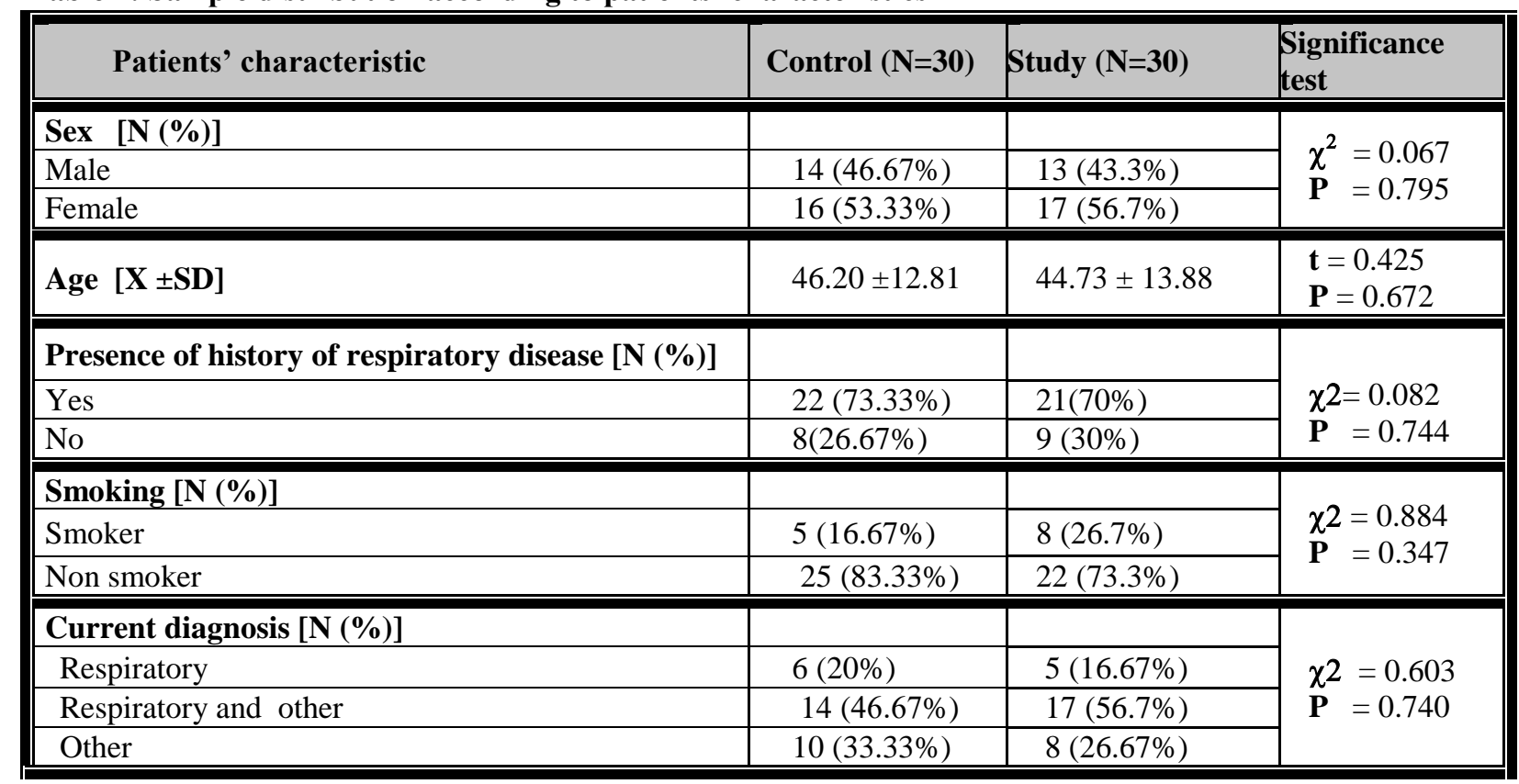

$* \mathrm{P}$ is significant if $\leq 0.05$

Table 2 reveals a comparison between the control and study groups as related to cardiac parameters including HR and MAP and respiratory parameters including RR and Vt at immediate before and 1, 10 and 30 min after ES. The results displayed that there was no significant statistical variance between the two groups immediately before suction regarding $\mathrm{HR}, \mathrm{MAP}, \mathrm{RR}$ and $\mathrm{Vt}(\mathrm{P}=0.547,0.588,0.573$ and 0.558 correspondingly). While after suctioning, HR increased in both groups with non-significant difference at 1,10 and $30 \mathrm{~min}$ ( $\mathrm{P}=0.370,0.344$ and 0.072 correspondingly), MAP decreased in both groups with non-significant difference at 1,10 and $30(0.562,0.635$ and 0.860 respectively), RR decreased significantly in control group at 1 and $10 \mathrm{~min}(\mathrm{P}=0.001$ and 0.040 correspondingly) and $\mathrm{Vt}$ increased significantly in study group at 1,10 and 30 $\min (\mathrm{P}=0.000,0.008$ and 0.010 correspondingly $)$.

Table 2: Comparison between the control and study groups as regards cardiac and respiratory parameters at immediate before and after endotracheal suction at different intervals.

\begin{tabular}{|c|c|c|c|c|c|c|}
\hline \multirow{2}{*}{\multicolumn{3}{|c|}{ Parameter $[\mathrm{X} \pm \mathrm{SD}]$ Group }} & \multirow{2}{*}{$\begin{array}{l}\text { Immediately } \\
\text { before suction }\end{array}$} & \multicolumn{3}{|c|}{ after suction } \\
\hline & & & & $1 \mathrm{~min}$ & $10 \mathrm{~min}$ & 30 min \\
\hline \multirow{4}{*}{$\begin{array}{l}\widehat{\Xi} \\
\stackrel{\Xi}{\varrho} \\
\mathfrak{\Xi}\end{array}$} & & $86.43 \pm 17.56$ & $96.43 \pm 20.29$ & $95.20 \pm 18.64$ & $96.67 \pm 15.30$ \\
\hline & \multicolumn{2}{|l|}{ Study } & $88.7 \pm 10.59$ & $92.10 \pm 16.73$ & $90.90 \pm 16.20$ & $88.57 \pm 15.16$ \\
\hline & \multirow{2}{*}{$\begin{array}{c}\text { Significance } \\
\text { test }\end{array}$} & $\mathbf{t}$ & 0.605 & 0.903 & 0.954 & 1.833 \\
\hline & & $\mathbf{p}$ & 0.547 & 0.370 & 0.344 & 0.072 \\
\hline \multirow{4}{*}{ 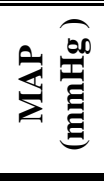 } & \multicolumn{2}{|l|}{ Control } & $96.37 \pm 16.58$ & $93.59 \pm 19.91$ & $92.41 \pm 20.65$ & $91.47 \pm 16.82$ \\
\hline & \multicolumn{2}{|l|}{ Study } & $96.69 \pm 21.26$ & $95.46 \pm 20.01$ & $94.95 \pm 20.49$ & $92.20 \pm 16.82$ \\
\hline & Significance & $\mathbf{t}$ & 0.065 & 0.362 & 0.477 & 0.177 \\
\hline & test & $\mathbf{p}$ & 0.948 & 0.719 & 0.635 & 0.860 \\
\hline \multirow{4}{*}{ 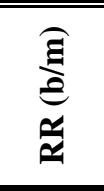 } & \multicolumn{2}{|l|}{ Control } & $18.17 \pm 4.57$ & $24.30 \pm 7.70$ & $20.80 \pm 7.54$ & $18.27 \pm 4.95$ \\
\hline & \multicolumn{2}{|l|}{ Study } & $19.10 \pm 7.761$ & $18.67 \pm 3.96$ & $17.60 \pm 3.53$ & $17.03 \pm 3.02$ \\
\hline & \multirow{2}{*}{$\begin{array}{c}\text { Significance } \\
\text { test }\end{array}$} & $\mathbf{t}$ & 0.568 & 3.564 & 2.106 & 1.165 \\
\hline & & $\mathbf{p}$ & 0.573 & $0.001 *$ & $0.040 *$ & 0.249 \\
\hline \multirow{4}{*}{$\underset{\overrightarrow{\mathbf{\Xi}}}{\widehat{\widehat{\mathbf{g}}}}$} & \multicolumn{2}{|l|}{ Control } & $486.87 \pm 56.22$ & $412.60 \pm 54.23$ & $464.10 \pm 82.12$ & $4779.50 \pm 65.20$ \\
\hline & \multicolumn{2}{|l|}{ Study } & $475.5 \pm 89.57$ & $526.10 \pm 116.54$ & $545.63 \pm 141.17$ & $546.80 \pm 122.78$ \\
\hline & \multirow{2}{*}{$\begin{array}{c}\text { Significance } \\
\text { test }\end{array}$} & $\mathbf{t}$ & 0.589 & 4.837 & 2.734 & 2.652 \\
\hline & & $\mathbf{p}$ & 0.558 & $0.000 *$ & $0.008 *$ & $0.010 *$ \\
\hline
\end{tabular}

HR: Heart rate. $\quad$ MAP: Mean arterial blood pressure. $\quad$ RR: respiratory rate $\quad \mathrm{V}_{\mathrm{t}}$ : Tidal volume. $* \mathrm{P}$ is significant if $\leq 0.05$ 
Table 3 reveals comparison between the control and study groups as regards gas exchange parameters as $\mathrm{PaO} 2, \mathrm{SaO} 2$ and $\mathrm{PaCO} 2$ at immediate before and 1, 10 and $30 \mathrm{~min}$ after ES. In relation to immediate presuction $\mathrm{PaO} 2, \mathrm{SaO} 2$ and $\mathrm{PaCO} 2$, there was no a significant statistical variance between the two groups $(\mathrm{P}=$ $0.865,0.991$ and 0.586 correspondingly). On the other hand in the study group, after suction $\mathrm{PaO} 2$ increased significantly at 1 and $10 \min (\mathrm{P}=0.001$ and 0.052 correspondingly) and $\mathrm{SaO} 2$ increased significantly at 1,10 and 30 min (0.000, 0.000 and 0.019 correspondingly). Regarding after suction PaCO2, there was no a statistical significant variance between the two groups at 1,10 and $30 \mathrm{~min}(\mathrm{P}=0.449,0.814$ and 0.906 correspondingly).

Table 3: Comparison between the control and study groups as regards gas exchange parameters at immediate before and after endotracheal suction at different intervals.

\begin{tabular}{|c|c|c|c|c|c|c|}
\hline \multirow{2}{*}{\multicolumn{3}{|c|}{$\begin{array}{l}\text { Gas exchange parameter } \\
{[\mathrm{X} \pm \mathrm{SP}]}\end{array}$}} & \multirow{2}{*}{$\begin{array}{c}\text { Immediately } \\
\text { before suction }\end{array}$} & \multicolumn{3}{|c|}{ After suction } \\
\hline & & & & $1 \mathrm{~min}$ & $10 \mathrm{~min}$ & $30 \mathrm{~min}$ \\
\hline \multirow{4}{*}{ 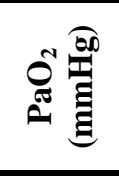 } & \multicolumn{2}{|l|}{ Control } & $97.09 \pm 37.22$ & $87.57 \pm 34.27$ & $97.15 \pm 38.33$ & $100.62 \pm 36.41$ \\
\hline & \multicolumn{2}{|l|}{ Study } & $95.25 \pm 40.89$ & $130.32 \pm 58.88$ & $117.96 \pm 42.78$ & $111.30 \pm 42.09$ \\
\hline & \multirow{2}{*}{ Significance Test } & $\mathbf{T}$ & 0.171 & 3.437 & 1.984 & 1.051 \\
\hline & & $\mathbf{P}$ & 0.865 & $0.001 *$ & $0.052 *$ & 0.297 \\
\hline \multirow{4}{*}{ 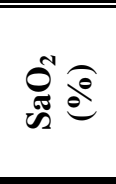 } & \multicolumn{2}{|l|}{ Control } & $94.31 \pm 3.50$ & $93.93 \pm 4.76$ & $93.92 \pm 4.20$ & $95.28 \pm 3.11$ \\
\hline & \multicolumn{2}{|l|}{ Study } & $94.81 \pm 3.61$ & $97.59 \pm 2.08$ & $97.35 \pm 2.39$ & $97.09 \pm 2.67$ \\
\hline & \multirow{2}{*}{ Significance Test } & $\mathbf{T}$ & 0.548 & 3.860 & 3.880 & 2.422 \\
\hline & & $\mathbf{P}$ & 0.586 & $0.000^{*}$ & $0.000 *$ & $0.019 *$ \\
\hline \multirow{4}{*}{ 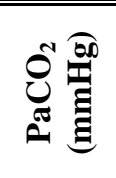 } & \multicolumn{2}{|l|}{ Control } & $36.71 \pm 14.50$ & $39.07 \pm 11.98$ & $37.12 \pm 15.02$ & $36.11 \pm 6.90$ \\
\hline & \multicolumn{2}{|l|}{ Study } & $36.75 \pm 15.14$ & $36.57 \pm 13.37$ & $36.19 \pm 15.51$ & $35.72 \pm 6.52$ \\
\hline & \multirow{2}{*}{ Significance Test } & $\mathbf{T}$ & 0.011 & 0.762 & 0.237 & 0.118 \\
\hline & & $\mathbf{P}$ & 0.991 & 0.449 & 0.814 & 0.906 \\
\hline
\end{tabular}

$\mathrm{PaO}_{2}$ : partial pressure of arterial oxygen

$\mathrm{SaO}_{2}$ : Arterial oxygen saturation
$\mathrm{PaCO}_{2}$ : partial pressure of arterial carbon dioxide $* \mathrm{P}$ is significant if $\leq 0.05$

\section{Discussion}

Results of this study showed that insignificant increase in HR in the control group more than in the study group and returned to the base status after $30 \mathrm{~min}$ in study group compared with before ES. This finding could be due to irritation by suction tube movements plus accompanied fear, pain and stress which are caused by ES technique itself. This was accepted by Keykha et al. ${ }^{(26)}$ who compared effect of standard ES and routine methods on vital signs, arterial blood oxygen saturation at ICU as they found that ES also caused increased HR in the two groups, but in study group, HR returned to the base status after five minutes. Also, Iranmanesh et al. ${ }^{(27)}$ and Ackerman ${ }^{(28)}$ indicated that HR elevated in the studied groups receiving ES with or without normal saline. Additionally, Lee et al. ${ }^{(29)}$ and Clark et al. ${ }^{(30)}$ approved that HR after ES elevated from its baseline. Contrary to this finding, Akbaryan Deheki et al. ${ }^{(31)}$ who compared three methods of suctioning with normal saline, $\mathrm{N}$-acetyl cysteine and without them reported that the level of HR and BP decreased after ES.

The current study illustrated that no significant decrease in MAP after ES in the two groups. Although MAP decrease was slightly lower in study group. This can be accepted as standard ES technique including: short time for MV disconnection and providing hyperoxygenation to avoid occurrence of hypoxemia as hypoxemia can result in hemodynamic instability. This result is in line with other studies ${ }^{(32,33)}$ which showed that there was no statistical significant difference in BP after ES with or without saline. Preusser et al. ${ }^{(34)}$ found through studying patients with coronary artery bypass grafting operation that oxygenation before ES resulted in low fluctuations in MAP readings.

Fisher et al. ${ }^{(35)}$ described in their study that elevation in BP next to ES. Parsons et al. ${ }^{(36)}$ evaluated the effect of hyperventilation at $100 \% \mathrm{O}_{2}$ followed by ES and found that MAP was significantly elevated above baseline. Ozden et al. 's ${ }^{(37)}$ study as well as Cereda et al. 's ${ }^{(38)}$ study illustrated that MAP increased following open ES. Moreover, Johnson et al. 's ${ }^{(39)}$ findings describing effect of open and closed endotracheal suctioning, MAP increased after ES in both groups. 
Effect of Application of Endotracheal Suction Guidelines on Cardiorespiratory Parameters of...

Concerning respiratory parameters, results of this study showed that RR decreased in the study group and increased in the control one with significant difference between them at immediate 1, and $10 \mathrm{~min}$ after suction. The result can be related to restlessness and suffering produced by ES technique. Futter et al. ${ }^{(40)}$ illustrated that there was a significant elevation in RR after ES resulting from suction producing suffering pain and restless. While, Alavi et al. ${ }^{\left({ }^{(33)}\right.}$ found that the effect of suction with as well as without normal saline on RR was negligible and changes were not significant.

Regarding $\mathrm{V}_{\mathrm{t}}$, it increased significantly in the study group in comparison with the control one after suction. It can be related to that in the study group, there was increased probabilities of improving inspired volume of air as evidenced by decreased time of patient's disconnection from ventilator, suctioning was done for 10 to 15 seconds, external diameter of the suction catheter was less than half of the internal diameter of the patient's tracheal tube, and suction pressure was controlled from 120 to $150 \mathrm{mmHg}$. Copnell B. et al. ${ }^{(22)}$ reported that the effect of suction method, force, and tube size on lung volume changes during ES in piglets and found that closed suction preserved more lung volume than open one.

In the current study, $\mathrm{PaO}_{2}$ and $\mathrm{SaO}_{2}$ increased significantly in the study group when compared with control group after ES. It can be understood through that the standard ES technique comprised MV disconnection short time and hyperoxygenation which helps to avoid hypoxemia. Kelleher $e t$ al. ${ }^{(41)}$ and Day et al. ${ }^{(42)}$ found that main deficiencies were related to failure to provide hyperoxygenation before as well as after ES procedure plus keeping suitable suction force. Bourgault et al. ${ }^{(47)}$ found that $\mathrm{PaO}_{2}$ elevated significantly post suctioning. Also, Sole et al. ${ }^{(19)}$ stated that increased $\mathrm{SaO}_{2}$ occurred after suctioning with the standard method. Moreover, other studies ${ }^{(38,43-46)}$ showed that longer time with ventilation interruption, loss of positive airway pressure, and reduction in lung volume lead to hypoxemia during open suctioning system.

Akgul ${ }^{(48)}$ and Najaf Yarandi ${ }^{(49)}$ and Akbaryan Deheki et al ${ }^{(31)}$ showed that $\mathrm{SaO}_{2}$ reduced after ES in both groups with and without normal saline. Also, Iranmanesh et al. ${ }^{(27)}$ reported that negative change in $\mathrm{SaO}_{2}$ was observed in the group who received ES with normal saline.

In the current study, there was nonsignificant increase in $\mathrm{PaCO}_{2}$ in the control group at 1 and 10 min after suction when compared with the study group. This may be related to that in control group, there was partial limitation in oxygen and carbon dioxide exchange during longer period of patient's disconnection from MV, non-constant administering 100\% oxygen before, between and after ES and decreased exhaled tidal volume. Zahran et al. ${ }^{\left({ }^{(5)}\right)}$ found significant increase in $\mathrm{PaCO}_{2}$ after ES with normal saline instillation. However Caramez

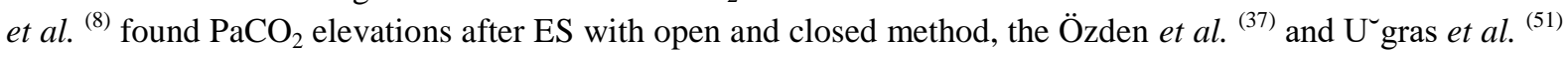
didn't

In addition, Kelher et al. ${ }^{(52)}$ showed that some nurses performed ES without consideration to recommended steps so excellence of this nursing intervention was less than predicted. Additionally, Jongerden et al. ${ }^{(3)}$ performed a practical study evaluating ES in which the suctioning procedure was done during standard way as needed based on advices. They found that ES wasn't linked with practically disorders in physiologic indicators.

\section{Conclusion}

From the present results, it can be concluded that MV patients who received ES with standard method based on the recommended guidelines had more stable heart rate, blood pressure, respiratory rate, improved tidal volume and arterial blood oxygenation.

\section{Recommendations}

Therefore this study recommends that regarding

\section{Clinical practice:}

- Nurses in ICU should closely observe $\mathrm{HR}, \mathrm{RR}, \mathrm{V}_{\mathrm{t}}$ and $\mathrm{SaO}_{2}$ during ES.

\section{Administration:}

- Modern apparatus for practicing and monitoring patients during ES correctly should be available in ICUs. 


\section{Education and training:}

- Conducting in-service education to nurses about standard ES raising their awareness on its advantage other than routine method

- Conducting in-service training about consideration for adhering strictly to steps of standard ES method such as providing $100 \%$ oxygen before-during-after the procedure, maximum of three ES pass, a maximum of 15 seconds suction for each suction pass and sufficient resting times to be given to patients between ES passes.

\section{References}

[1] Harada N. Closed suctioning system: Critical analysis for its use. Japan Journal of Nursing Science 2010; 7:19-28.

[2] Mohammadpour A, Amini S, Shakeri MT, Mirzaei S. Comparing the effect of open and closed endotracheal suctioning on pain and oxygenation in post CABG patients under mechanical ventilation. Iranian Journal of Nursing and Midwifery Research Mar-Apr 2015; 20(2):195-9.

[3] Jongerden IP, Kesecioglu J, Speelberg B, Buiting AG, Leverstein-van Hall MA, Bonten MJ. Changes in heart rate, mean arterial pressure, and oxygen saturation after open and closed endotracheal suctioning: A prospective observational study. Journal of Critical Care 2012; 27:647-54.

[4] Herbst-Rodrigues MV, Carvalho VO, Auler JO, Feltrim MI. PEEP-ZEEP technique: Cardiorespiratory repercussions in mechanically ventilated patients submitted to a coronary artery bypass graft surgery. Journal of Cardiothoracic Surgery 2011; 6:108.

[5] Credland N. How to perform open tracheal suction via an endotracheal tube. Nursing Standard 2016; 30(35):30-8.

[6] Patak L, Gawlinski A, Fung I, Doering L, Berg J. Patients' reports of health care practitioner interventions that are related to communication during mechanical ventilation. Heart Lung 2004; 33: 308-21.

[7] Negroa A, Ranzani R, Villaa M, Manara D. Survey of Italian intensive care unit nurses' knowledge about endotracheal suctioning guidelines. Intensive and Critical Care Nursing 2014; 30:339-45.

[8] Caramez MP, Schettino G, Suchodolski K, Nishida T, Harris RS, Malhotra A, Kacmarek RM. The impact of endotracheal suctioning on gas exchange and hemodynamics during lung protective ventilation in acute respiratory distress syndrome. Respiratory Care May 2006; 51(5):497-502.

[9] Day T, Farnell S, Wilson-Barnett J. Suctioning: a review of current research recommendations. Intensive CritIcal Care Nursing 2002; 18(2):79-89.

[10] Pedersena CM , Rosendahl-Nielsenb M, Hjermindc J , Egerodd I. Endotracheal suctioning of the adult intubated patientWhat is the evidence? Intensive and Critical Care Nursing 2009;25:21-30.

[11] Scoble MK, Copnell B, Taylor A, Kinney S, Shann F. Effect of reusing suction catheters on the occurrence of pneumonia in children. Heart Lung 2001; 30(3):225-33.

[12] Ansari A, Alavi NM, Adib-Hajbagheri M, Afazel M. The gap between knowledge and practice in standard endo-tracheal suctioning of ICU nurses, Shahid Beheshti Hospital. Iranian Journal of Critical Care Nursing 2012; 5(2):71-6.

[13] AARC clinical practice guideline: endotracheal suctioning of mechanically ventilated patients with artificial airways. Respiratory Care 2010; 55(6):758-64.

[14] Özden D, Görgülü RS. Development of standard practice guidelines for open and closed system suctioning. Journal of Clinical Nursing 2012; 21:1327-38.

[15] McKillop A. Evaluation of the implementation of a best practice information sheet: tracheal suctioning of adults with an artificial airway. Joanna Briggs Institute Reports 2004; 2:293-308.

[16] Linda C.H, Chang AM. Are nurses using best practice in tracheal suctioning of artificial airways? Australian Critical Care February 2009;22(1):53. DOI: http://dx.doi.org/10.1016/j.aucc.2008.12.028

[17] Day T, Farnell S, Haynes S, Wainwright S, and Wilson-Barnett J. Tracheal suctioning: an exploration of nurse's knowledge and competence in acute and high dependency ward areas. Journal of Advanced Nursing 2002; 39:35-45.

[18] Çelik SS, Elbas NO. The standard of suction for patients undergoing endotracheal intubation. Intensive and Critical Care Nursing $2000 ; 16,191-8$.

[19] Sole ML, Byers JF, Ludy JE, Zhang Y, Banta CM, Brummel K. A multisite survey of suctioning techniques and airway management practices. American Journal of Critical Care 2003; 12(3):220-30.

[20] Day T, Iles N, Griffiths P. Effects of performance feedback on tracheal suctioning knowledge and skills: randomized controlled trial. Journal of Advanced Nursing 2009:682-96.

[21] Jansson M, Ala-Kokko T, Ylipalosaari P, Kyngäs H. Evaluation of endotracheal-suctioning practices of critical-care nurses - An observational correlation study. Journal of Nursing Education and Practice. 2013; 3(7): 99-105.

[22] Copnell B, Dargaville PA, Ryan EM, Kiraly NJ, Chin LOF, Mills JF, Tingay DG. The effect of suction method, catheter size, and suction pressure on lung volume changes during endotracheal suction in piglets. International Pediatric Research Foundation, Inc. 2009; 66(4):405-10.

[23] Keykha A, Askari H, Abbaszadeh A, Enayatie H, Hosini BM, Borhani F. Comparing the effects of standard suction and routine methods on vital signs, arterial blood oxygen saturation and pain level of patients hospitalized at the intensive care unit. Critical Care Nursing Journal May 2016; 9(2):e6619.

[24] Kotz S, Balakrishnan N, Read CB, Vidakovic B. Encyclopedia of statistical sciences. 2nd ed. Hoboken, N.J.: Wiley-Interscience; 2006.

[25] Kirkpatrick LA, Feeney BC. A simple guide to IBM SPSS statistics for version 20.0. Student ed. Belmont, Calif.: Wadsworth, Cengage Learning; 2013. 
[26] Akbar Keykha A, Abbaszadeh A, Enayati H, Borhani F, Rafiei H, Khodadadi Hoseini BM. Applying the instruction of pain control and sedation of the patients hospitalized in intensive care unit. Iranian Journal of Critical Care Nursing 2014; 6(4):243-50.

[27] Iranmanesh S. Comparison of the endotracheal tube suctioning with and without normal saline solution on heart rate and oxygen saturation. Iranian Journal of Critical Care Nursing 2011; 4(3):117-20.

[28] Ackerman M H. The effect of normal saline lavage prior to suctioning in adults. A thesis submitted in partial fulfilment of the requirements for the doctoral degree of Science in Nursing. State University of New York at Buffalo 1991; 121.

[29] Lee C, Ng K, Tan S. Ang R. Effect of different endotracheal suctioning systems on cardiorespiratory parameters of ventilated patients. Annals Academy of Medicine Singapore 2001; 30:239-44.

[30] Clark A, Tyler D and White K. Effects of endotracheal suctioning on mixed venous oxygen saturation and heart rate in critically ill adults. Heart \& Lung 1990; 19:552-7.

[31] Akbaryan Deheki N, Sanagoo A, Amri P, Moghaddam S, Vakili MA, Nasiri H, et al. Comparing the effect of using normal saline, Nacetyl cysteine and not using them in endotracheal tube suction on physiologic parameters and the amount of secretions in intubated patients under mechanical ventilation. Iranian Journal of Critical Care Nursing 2014;6(4):152-9.

[32] Favretto DO, Silveira RC, Canini SR, Garbin LM, Martins FT, Dalri MC. Endotracheal suction in intubated critically ill adult patients undergoing mechanical ventilation: a systematic review. Revista latino-americana de enfermagem 2012; 20(5):997-1007.

[33] Adib M, Ghanbari A, Alavi CE, Leyli EK. Effect of endotracheal suctioning with and without normal saline on hemodynamic and respiratory parameters in patients undergoing mechanical ventilation in ICU of hospitals supervised by Guilan University of Medical Sciences. Biomedical \& Pharmacology Journal 2014; 7(2):515-23.

[34] Preusser B, Stone K, Gonyon D. Effects of two methods of preoxygenation on mean arterial pressure, cardiac output, peak airway pressure and post suctioning hypoxemia. Heart Lung 1988; 17(3):290-9.

[35] Fisher DM, Frewen T, Swedlow DB. Increase in intracranial pressure during suctioning stimulation vs. rise in $\mathrm{PaCO}_{2}$. Anesthesiology 1982; 57:416-7.

[36] Parsons LC, Ouzts-Shogan JS. The effects of the endotracheal tube suctioning / manual hyperventilation procedure on patients with severe closed head injuries. Heart \& Lung 1984; 13:372-80.

[37] Özden D, SGörgülü R. Effects of open and closed suction systems on the haemodynamic parameters in cardiac surgery patients. Nursing in Critical Care published by John Wiley \& Sons, Ltd on behalf of British Association of Critical Care Nurses 2014;20(3):118-25.

[38] Cereda M, Villa F, Colombo E, Greco G, Nacoti M, Pesenti A. Closed system endotracheal suctioning maintains lung volume during volume-controlled mechanical ventilation. Intensive Care Medicine 2001; 27:648-54.

[39] Johnson KL, Kearney PA, Johnson SB, Niblett JB, MacMillan NL, McClain RE. Closed versus open endotracheal suctioning: costs and physiologic consequences. Critical Care Medicine 1994; 22:658-66.

[40] Futter M, Morrow B, Argent A. Effect of endotracheal suction on lung dynamics in mechanically-ventilated paediatric patients. Journal of Physiotherapy 2006; 52:121-6.

[41] Kelleher S, Andrews T. An observational study on the open-system endotracheal suctioning practices of critical care nurses. Journal of Clinical Nursing 2008; 17:360-9.

[42] Day T, Farnell S, Haynes S, Wainwright S, and Wilson-Barnett J. Tracheal suctioning: an exploration of nurse's knowledge and competence in acute and high dependency ward areas. Journal of Advanced Nursing 2002; 39: 35-45.

[43] Fernandez MD, Piacentini E, Blanch L, Fernandez R. Changes in lung volume with three systems of endotracheal suctioning with and without preoxgynation in patients with mild-to-moderate lung failure. Intensive Care Medicine 2004; 30:2210-5.

[44] Briassoulis G, Briassoulis P, Michaeloudi E, Fitrolaki DM, Spanaki AM, Briassouli E. The effects of endotracheal suctioning on the accuracy of oxygen consumption and carbon dioxide production measurements and pulmonary mechanics calculated by a compact metabolic monitor. Anesthesia \& Analgesia 2009; 109: 873-9.

[45] Pirr SM, Lange M, Hartmann C, Bohnhorst B, Peter C. Closed versus open endotracheal suctioning in extremely low-birth-weight neonates: A randomized, crossover trial. Neonatology 2013; 103:124-30.

[46] Yazdannik AR, Haghighat S, Saghaei M, Eghbali M. Comparing two levels of closed system suction pressure in ICU patients: Evaluating the relative safety of higher values of suction pressure. Iranian Journal of Nursing and Midwifery Research 2013; $18: 117-22$

[47] Bourgault A, Brown C, Hains S, Parlow J. Effects of endotracheal tube suctioning on arterial oxygen tension and heart rate variability. Biological Research for Nursing 2006; 7:268-78.

[48] Akgül S, Akyolcu N. Effects of normal saline on endotracheal suctioning. Journal of Clinical Nursing 2002; 11(6):826-30

[49] Najaf yarandi A, Tanourifard M, Nikpour S, Haghani H. The effects of Endotracheal suctioning with normal saline on arterial blood gases Iranian Journal of Nursing and Midwifery Research 2000;28:39-46.

[50] Zahran EM, El-Razik AA. Tracheal suctioning with versus without saline instillation. Journal of American Science 2011; 7(8):23-32.

[51] U gras, G and Aksoy G. The effects of open and closed endotracheal suctioning on intracranial pressure and cerebral perfusion pressure: a crossover, single-blind clinical trial. Journal of Neuroscience Nursing 2012; 44: E1-E8.

[52] Kelleher S, Andrews T. An observational study on the open-system endotracheal suctioning practices of critical care nurses. Journal of Clinical Nursing. 2008; 17(3):360-9. 